Article

\title{
Preparation and Characterization of Regenerated Cellulose Film from a Solution in Lithium Bromide Molten Salt Hydrate
}

\author{
Xueqin Zhang ${ }^{1,2,3}$, Naiyu Xiao ${ }^{1, *}$, Huihui Wang ${ }^{2}$, Chuanfu Liu ${ }^{2, *(\mathbb{D})}$ and Xuejun Pan ${ }^{3}$ \\ 1 College of Light Industry and Food, Zhongkai University of Agriculture and Engineering, \\ Guangzhou 510225, China; xueqin0228@gmail.com \\ 2 State Key Laboratory of Pulp and Paper Engineering, South China University of Technology, \\ Guangzhou 510640, China; wang.huihui@mail.scut.edu.cn \\ 3 Department of Biological System Engineering, University of Wisconsin-Madison, 460 Henry Mall, Madison, \\ WI 53706, USA; xpan@wisc.edu \\ * Correspondence: xiaony81@163.com (N.X.); chfliu@scut.edu.cn (C.L.); \\ Tel.: +86-20-8900-2852 (N.X.); +86-20-8711-1735 (C.L.)
}

Received: 27 April 2018; Accepted: 1 June 2018; Published: 4 June 2018

check for updates

\begin{abstract}
In this study, the molten salt hydrate of lithium bromide ( $\mathrm{LiBr}$ ) was utilized as a non-derivatizing cellulose dissolution solvent to prepare regenerated cellulose films for kraft pulp. The effects of $\mathrm{LiBr}$ concentrations $(60,62$, and $65 \mathrm{wt} \%$ ) and dissolving time (from 5 to $40 \mathrm{~min}$ with the interval of $5 \mathrm{~min}$ ) on the structures and the properties of the films were investigated. Fourier transform infrared (FT-IR) and cross-polarization magic-angle spinning carbon-13 nuclear magnetic resonance $\left(\mathrm{CP} / \mathrm{MAS}{ }^{13} \mathrm{C} \mathrm{NMR}\right)$ characterizations verified the breakage of inter- and intra-cellulose hydrogen bonds during the regeneration, resulting in the disruption of the crystalline structure of cellulose. $\mathrm{X}$-ray diffraction (XRD) data indicated that the regeneration converted the polymorphism of cellulose from I to II as well as decreased its crystallinity. Ultraviolet-visible spectra (UV-Vis) and scanning electron microscopy (SEM) analyses revealed the excellent optical transparency of the films to visible light due to the complete dissolution of cellulose fibers as well as the sufficient breaking of the interand intra-cellulose hydrogen bonds. In terms of tensile testing, tuning $\mathrm{LiBr}$ concentrations and dissolving time could increase the elongation at break and tensile strength of the films. The maximum elongation at break of $26 \%$ and tensile strength of $67 \mathrm{MPa}$ were achieved when the films prepared in $65 \mathrm{wt} \% \mathrm{LiBr}$ for 10 and $15 \mathrm{~min}$, respectively. These results indicated the great potential of the cellulose films for packaging use.
\end{abstract}

Keywords: inorganic ionic liquid; kraft pulp; non-derivatizing dissolution; packaging film

\section{Introduction}

With the urgent demand to address the energy and environment issues that are caused by using fossil resources, there have been increasing interests in exploring biomass-based renewable and sustainable materials. Cellulose, a linear polymer of glucose with linkage of $\beta-1,4$-glycosidic bond, is the most abundant polysaccharide on earth, and has been utilized for various types of biocomposites [1]. Among which, cellulose-based films have drawn considerable attention for packaging, including food packaging [2,3], because of their optical transparency, tunable porous structure, and good mechanical properties [4]. However, the insolubility of natural cellulose in water and common organic solvents due to the highly crystalline structure makes it very challenging to prepare the films directly from celluloses [5]. 
In recent years, many solvent systems have been developed to negate the dissolution recalcitrance of cellulose to prepare regenerated films [4]. Generally, the solvent systems can be divided into derivatizing and non-derivatizing ones [6]. Non-derivatizing solvent systems have been extensively studied for dissolving and regenerating cellulose, as well as developing advanced and homogeneous cellulose derivatives [6]. A well-known cellulose non-derivatizing solvent system is $\mathrm{N}, \mathrm{N}$-dimethylacetamide (DMAc) or its cyclic form, 1-methyl-2-pyrrolidinone (NMP) with lithium chloride $(\mathrm{LiCl})[7,8]$. It was reported that this solvent with the concentration of $\mathrm{LiCl} 1-10 \mathrm{wt} \%$ was able to dissolve cellulose up to 10-15 wt \% [9]. Ionic liquids, firstly proposed by Rogers in 2002, is another cellulose non-derivatizing solvent system [10]. So far, ionic liquids have been comprehensively studied in the areas of dissolving and derivatizing lignocelluloses [11-13]. Compared to $10 \mathrm{wt} \% \mathrm{DMAc} / \mathrm{LiCl}$, an ionic liquid, such as 1-buthyl-3-methylimidazolium chloride $\left(\left[\mathrm{C}_{4} \mathrm{mim}\right] \mathrm{Cl}\right)$, had almost three times more free chloride ion concentration, which played a crucial role in breaking the hydrogen-bonding network in cellulose [10]. The third well-known solvent system is $\mathrm{NaOH}$ - or $\mathrm{LiOH}$-urea aqueous system working at low-temperature, which was developed by Zhang's research group [14,15]. Additional examples of non-derivatizing solvents include $N$-methyl- $N$-morpholine- $N$-oxide (NMMO)/water [16], concentrated phosphoric acid [17], and aqueous $\mathrm{NaOH}$ solutions [18]. However, these solvents still more or less suffered from different drawbacks, such as the environmental problems, complicated multistep processes, or high price $[19,20]$.

Molten salt hydrates have been recently found to be as an economic, recyclable, and non-toxic non-derivatizing solvent system for cellulose [21]. Unlike many non-derivatizing solvents, cellulose dissolution in molten salt hydrates did not require pretreatment, which makes molten salt hydrate an attractive cellulose solvent [22]. In a molten salt hydrate, the water-salt molar ratio is close to the coordination number of the strongest hydrated ion, normally a cation [23]. The molten salt hydrates reported to be able to dissolve cellulose include $\mathrm{ZnCl}_{2} \cdot 4 \mathrm{H}_{2} \mathrm{O}, \mathrm{LiI} \cdot 2 \mathrm{H}_{2} \mathrm{O}, \mathrm{LiSCN} \cdot 2 \mathrm{H}_{2} \mathrm{O}$, as well as a eutectic mixture of $\mathrm{NaSCN} / \mathrm{KCN} / \mathrm{LiSCN} \cdot 3 \mathrm{H}_{2} \mathrm{O}$ [22,24]. The dissolving capacity of molten salt hydrates mainly depends on the species of the molten salts, the state of the solution, and the water content.

The molten salt of hydrate lithium bromide (concentrated aqueous solution of LiBr), which is usually used as liquid desiccants for its low water vapor pressure [25], was recently found to be able to dissolve cellulose and was used in the regeneration, functionalization, and hydrolysis of cellulose $[17,26,27]$. It was observed that the cellulose-LiBr solution could easily form a gel when the solution was cooled down to approximately $70^{\circ} \mathrm{C}$. Cellulose biocomposites could be then easily fabricated after removing the salts via water washing [17].

In this study, cellulose films from kraft pulp were prepared by direct dissolution and the regeneration of cellulose in $\mathrm{LiBr}$ molten salt hydrate. The effects of $\mathrm{LiBr}$ concentrations and dissolving time on the structures and properties of the resultant cellulose films were investigated. From our preliminary experiments, the results (not shown here) indicated that cellulose could not be dissolved in $\mathrm{LiBr}$ solution with concentrations that were less than $60 \mathrm{wt} \%$ within $1 \mathrm{~h}$. In addition, when the concentration of $\mathrm{LiBr}$ solution is higher than $65 \mathrm{wt} \%$, the $\mathrm{LiBr}$ solids will be precipitated at room temperature. Therefore, the LiBr molten salt hydrates with the concentrations of $60 \mathrm{wt} \%, 62 \mathrm{wt} \%$, and $65 \mathrm{wt} \%$ were used in this study. The regenerated cellulose films were thoroughly characterized by using Fourier transform infrared (FT-IR), cross-polarization magic-angle spinning carbon-13 nuclear magnetic resonance $\left(\mathrm{CP} / \mathrm{MAS}{ }^{13} \mathrm{C} \mathrm{NMR}\right)$, Ultraviolet-visible spectra (UV-Vis), scanning electron microscopy (SEM), and X-ray diffraction (XRD) analyses. The optical and mechanical strength of the films were evaluated as well. 


\section{Materials and Methods}

\subsection{Materials}

A bleached hardwood kraft pulp was used as cellulose source. The pulp board was shredded and soaked in distillated water at room temperature for $24 \mathrm{~h}$. Then, it was mechanically disintegrated and freeze dried for later use. The average degree of polymerization (DP) of cellulose was 768 , determined using viscosity method following the GB/T 1548-2016 standard method.

$\mathrm{LiBr}(99 \%)$ was purchased from Macklin Reagent Co. (Shanghai, China). Aqueous LiBr solutions with various concentrations $(60,62$, and $65 \mathrm{wt} \%$ ) were prepared by dissolving $\mathrm{LiBr}$ in water.

\subsection{Cellulose Film Preparation in Aqueous Libr Solutions}

A typical process for preparing cellulose film was as follows. First, $0.2 \mathrm{~g}$ cellulose was stirred in $15 \mathrm{~g} \mathrm{LiBr}$ molten salt hydrate solution at room temperature for about $3 \mathrm{~h}$ to ensure the full swelling of the cellulose. Then, the mixture was heated up to $130^{\circ} \mathrm{C}$ to dissolve the cellulose. After that, the solution was quickly cast onto a glass plate to get a hydrogel, which was immediately immersed into deionized water to completely remove $\mathrm{LiBr}$ (confirmed by the $\mathrm{AgNO}_{3}$ test). The obtained transparent gel was pressed between two filter papers and then dried naturally in air to get a cellulose film. Films were named as $\mathrm{x}-\mathrm{y}$, according to their fabrication conditions. The $\mathrm{x}$ stands for the concentration of $\operatorname{LiBr}(\%)$ and $y$ is the dissolution time (min). For example, sample $65 \%-5$ represents the film that was prepared in $65 \mathrm{wt} \% \mathrm{LiBr}$ with dissolution time of $5 \mathrm{~min}$.

\subsection{Characterization}

Fourier transform infrared (FT-IR) spectra were obtained in the range of 4000-500 $\mathrm{cm}^{-1}$ on a Tensor 27 spectrophotometer (Bruker, Karlsruhe, Germany) in KBr disc containing 1\% (w/w) of finely ground sample. Thirty-two scans were applied with $4 \mathrm{~cm}^{-1}$ resolution in the transmittance mode.

Solid-state cross-polarization magic-angle spinning carbon-13 nuclear magnetic resonance $\left(\mathrm{CP} / \mathrm{MAS}{ }^{13} \mathrm{C}\right.$ NMR) analysis was performed on a Bruker AVANCE III 600 spectrometer (Karlsruhe, Germany) at a resonance frequency of $150.9 \mathrm{MHz}$. The MAS probe of $4 \mathrm{~mm}$ and the spinning rate of $12 \mathrm{kHz}$ were used. The contact time was $3 \mathrm{~ms}$ and the recycle delay was $3 \mathrm{~s}$. The chemical shifts of ${ }^{13} \mathrm{C}$ were externally referenced to TMS.

Ultraviolet-visible spectra (UV-Vis) were recorded on a TU-1810 spectrophotometer (Beijing, China) within the scan range of 200 to $900 \mathrm{~nm}$.

The surface morphology of films was observed by using scanning electron microscopy (SEM) on a LEO 1530 VP equipment (Oberkochen, Germany) with an accelerating voltage of $10 \mathrm{kV}$. Cellulose film sample was attached onto a mica sheet followed by gold-plating for SEM observation.

The tensile strength of the prepared films was tested using rectangular specimens $(15 \mathrm{~mm} \times 10 \mathrm{~mm})$ on an Instron Universal Testing Machine 5565 (Instron, Norwood, MA, USA) with a $100 \mathrm{~N}$ load cell at $23{ }^{\circ} \mathrm{C}$ and $50 \% \mathrm{RH}$. Five replicate specimens were tested for each film sample. The initial distance between the two grips was $30 \mathrm{~mm}$ and the separation rate of the grips was $4 \mathrm{~mm} / \mathrm{min}$.

The crystallinity of samples was characterized by X-ray diffraction (XRD) measurement on a D/max-III X-ray diffractometer (Rigaku, Tokyo, Japan), equipped with nickel-filtered $\mathrm{Cu} \mathrm{K} \alpha$ radiation $(\lambda=0.15418)$. The diffraction angle $(2 \theta)$ ranged from $5^{\circ}$ to $40^{\circ}$ and the step size was $0.04^{\circ}$. Lorentz deconvolution was used for peak separations. The $d$-spacings $(d)$ of films were calculated with the Bragg equation [28]:

$$
d=\frac{\lambda}{2 \sin \theta}
$$

where $\lambda$ is the wavelength of the $\mathrm{X}$-ray source $(0.15418 \mathrm{~nm})$ and $\theta$ is the Bragg angle corresponding to the plane.

The apparent crystallite size $(L)$ of the reflection plane was obtained using the Scherrer equation [29]: 


$$
L=\frac{K \lambda}{\beta \cos \theta}
$$

where $K$ is the Scherrer constant of 0.94 and $\beta$ is the half-height width of the diffraction band.

The surface chains of cellulose crystals occupy a layer approximately $0.57 \mathrm{~nm}$ thick $(h)$; therefore, the proportion of crystallite interior chains $(X)$ was calculated with the following equation [30]:

$$
X=\left(\frac{L-2 h}{L}\right)^{2}
$$

The Segal crystalline index (CrI) [31] was calculated, as follows:

$$
\mathrm{CrI}=\frac{I_{200}-I_{a m}}{I_{200}}
$$

where $I_{200}$ is the intensity of the peak at $2 \theta \approx 22^{\circ}$ corresponding to (200) and $I_{a m}$ is the amorphous intensity at $2 \theta \approx 18^{\circ}$ for cellulose I and $2 \theta \approx 16^{\circ}$ for cellulose II.

\section{Results and Discussion}

\subsection{FT-IR Analysis}

FT-IR was used to investigate the changes in chemical structure of cellulose during the dissolution and regeneration in LiBr molten salt hydrate. As shown in Figure 1A, the main functional groups in cellulose were detected at the wavenumbers of 3324 (O-H hydroxyl group stretching vibration), 2895 ( $-\mathrm{CH}_{2}-$ alkyl stretching vibration), 1421 ( $-\mathrm{CH}_{2}-$ alkyl bending stretching), 1155 (C-O-C pyranose ring skeletal vibrations), 1020 (C-O stretching) and $892 \mathrm{~cm}^{-1}$ ( $\beta$-glucosidic linkages between the sugar units), respectively. The absorption at $1634 \mathrm{~cm}^{-1}$ is attributed to the absorbed water. The same characteristic bands of cellulose were observed on the spectra of the regenerated films (62\%-25, 65\%-25, and $65 \%-35$ ), indicating that cellulose structure did not change during the dissolution and regeneration. This observation verified the non-derivatizing nature of $\mathrm{LiBr}$ molten salt hydrate as cellulose solvent. However, the O-H stretching vibration shifted to a higher wavenumber domain of $3357 \mathrm{~cm}^{-1}$, which was probably due to the decreased hydrogen bonding in cellulose after regeneration [32]. Moreover, the intensity of the weak absorption at $892 \mathrm{~cm}^{-1}$ attributed to the $\mathrm{C}-\mathrm{H}$ deformation at anomeric center of $\beta$-glucosidic linkages increased, which was in agreement with the previous results [17].
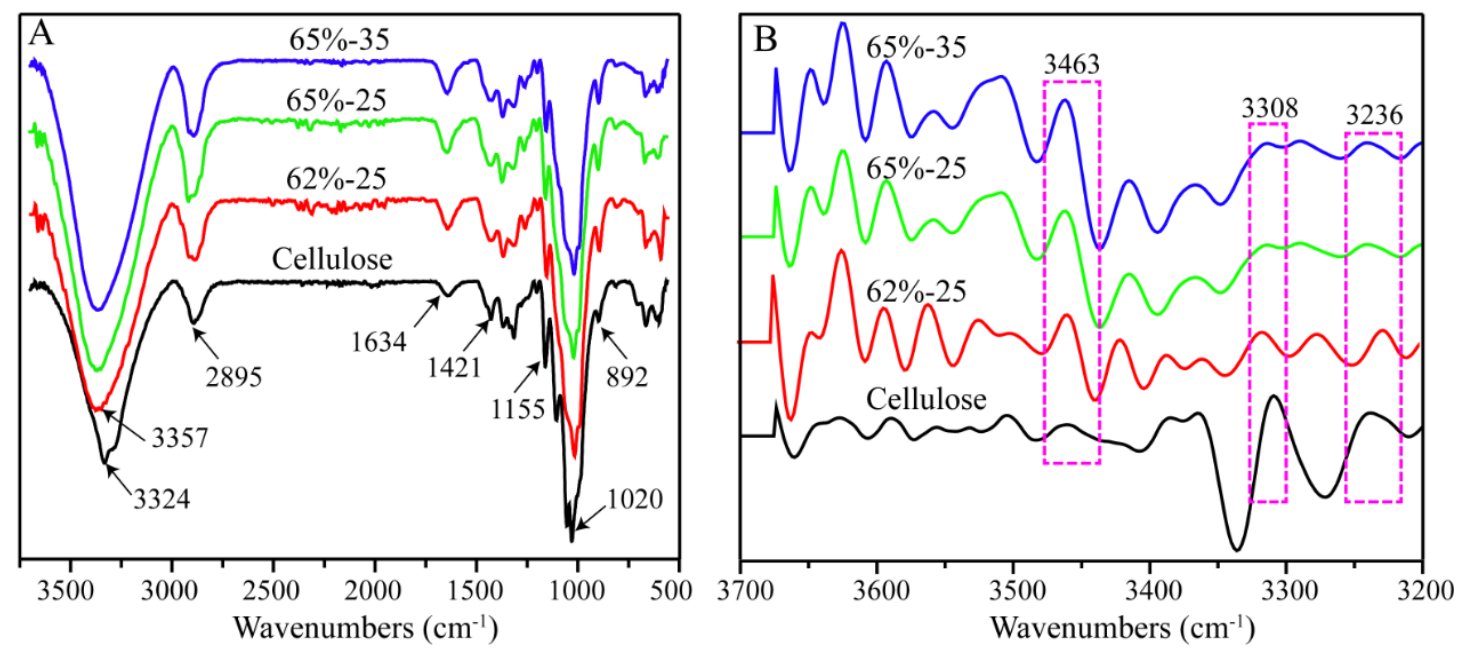

Figure 1. Fourier transform infrared (FT-IR) spectra (A) and relative second-derivative FT-IR spectra (B) of cellulose samples. 
The second-derivatives of FT-IR spectra were conducted to further confirm the changes of hydrogen bonding of cellulose upon regeneration. Apparently, the intensity of peaks at 3236 (the interchain $\mathrm{O} 2-\mathrm{H} \cdots \mathrm{O} 6$ bonding of $\mathrm{I}_{\beta}$ ) and $3308 \mathrm{~cm}^{-1}$ (the $\mathrm{O} 2-\mathrm{H} \cdots \mathrm{O} 6-\mathrm{H} \cdots \mathrm{O} 3-\mathrm{H} \cdots \mathrm{O} 5$ bonding) decreased, while that of the band at $3463 \mathrm{~cm}^{-1}$ increased (the $\mathrm{OH}$ groups with weak hydrogen bonding in the semicrystalline domains [33]). These results indicated that the dissolution and the regeneration of cellulose in $\mathrm{LiBr}$ molten salt hydrate weakened or broke the inter- and intra-cellulose hydrogen bonding, and thereby disrupted its crystalline structure. In addition, the effects increased with the severity of the treatment conditions.

\section{2. $C P / M A S{ }^{13} C$ NMR Analysis}

The $\mathrm{CP} / \mathrm{MAS}{ }^{13} \mathrm{C}$ NMR spectra of cellulose and regenerated cellulose films are shown in Figure 2. The ${ }^{13} \mathrm{C}$ NMR spectrum of native cellulose has four signal clusters: the region at 102-108 ppm assigned to $C 1$ moieties; the two signals at the region of 79-92 ppm assignable to $C 4$ moieties due to amorphous (83 ppm) and crystalline (89 ppm) states, respectively; a cluster of signals from C2, C3, and C5 carbons (68-79 ppm); and, that in the region at 57-68 ppm including a broad signal at $63 \mathrm{ppm}$ and a sharp signal at $65 \mathrm{ppm}$ assignable to C6 moieties for the amorphous and crystalline states, respectively. For the regenerated cellulose films, the structures of the glucose rings of cellulose retained intact, verifying again the non-derivatizing dissolution of cellulose in $\mathrm{LiBr}$ molten salt hydrate. However, the regenerated films had overlapping signals of C2, C3, and C5 (68-79 ppm), accompanied by the disappearance of the signals at 89 and $65 \mathrm{ppm}$ for the crystalline structure at $\mathrm{C} 4$ and $\mathrm{C} 6$, as well as the decreased intensity of the amorphous signals at C4 (83 ppm) and C6 (63 ppm), respectively, indicating the disruption of the crystalline structure of cellulose after dissolution and regeneration in LiBr molten salt hydrate [17].

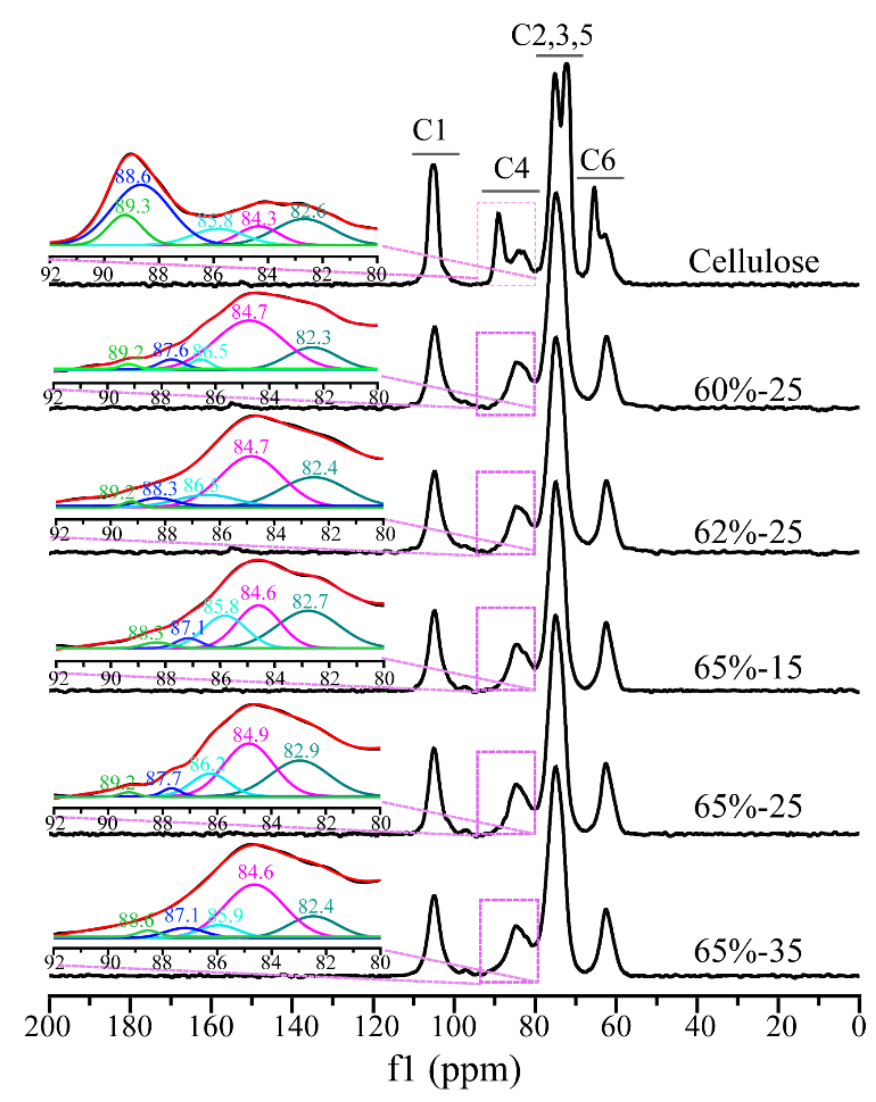

Figure 2. Cross-polarization magic-angle spinning carbon-13 nuclear magnetic resonance (CP/MAS ${ }^{13} \mathrm{C}$ NMR) spectra of cellulose samples. 
In general, when cellulose crystallinity is lower than $50 \%$, it is not reliable to compare the difference of cellulose polymorphs using C6 resonance [34]. Alternatively, C4 signal could be used [35]. Therefore, the Gaussian deconvolution of $\mathrm{C} 4$ signal was adopted to investigate the polymorphs difference of cellulose during the dissolution and regeneration, as shown in Figure 2. When compared to the original cellulose, the intensity of the signals at 89.3 and $88.6 \mathrm{ppm}$ for cellulose $I_{\alpha}$ and cellulose $I_{\beta}$, respectively, of regenerated cellulose dramatically decreased, while that of the signal at $84.6 \mathrm{ppm}$ attributing to accessible crystallite surfaces increased. These results further confirmed the disruption of crystallite structure of cellulose during the dissolution and regeneration in LiBr molten salt hydrate, which is consistent with the FT-IR data above.

\subsection{XRD Analysis}

XRD was carried out to compare the crystallinity of cellulose before and after the regeneration, as shown in Figure 3. The original cellulose displayed a typical cellulose I XRD pattern with the specific peaks, as is consistent with the literature [36]. The regenerated films presented typical cellulose II characteristics with peaks at about $2 \theta=12.2^{\circ}$ and $20.4^{\circ}$, associating to (110) and (110) planes, respectively, indicating the transformation of the crystal structure from cellulose I to cellulose II upon the dissolution and regeneration [23]. The Lorentz deconvolution process was applied to distinguish amorphous and crystalline contributions to the diffraction spectrum. The related parameters, including $d$-spacings $(d)$, the crystallite size $(L)$, the proportion of crystallite interior chains $(X)$, and the crystallinity index (CrI) were calculated from XRD profiles and are summarized in Tables 1 and 2.
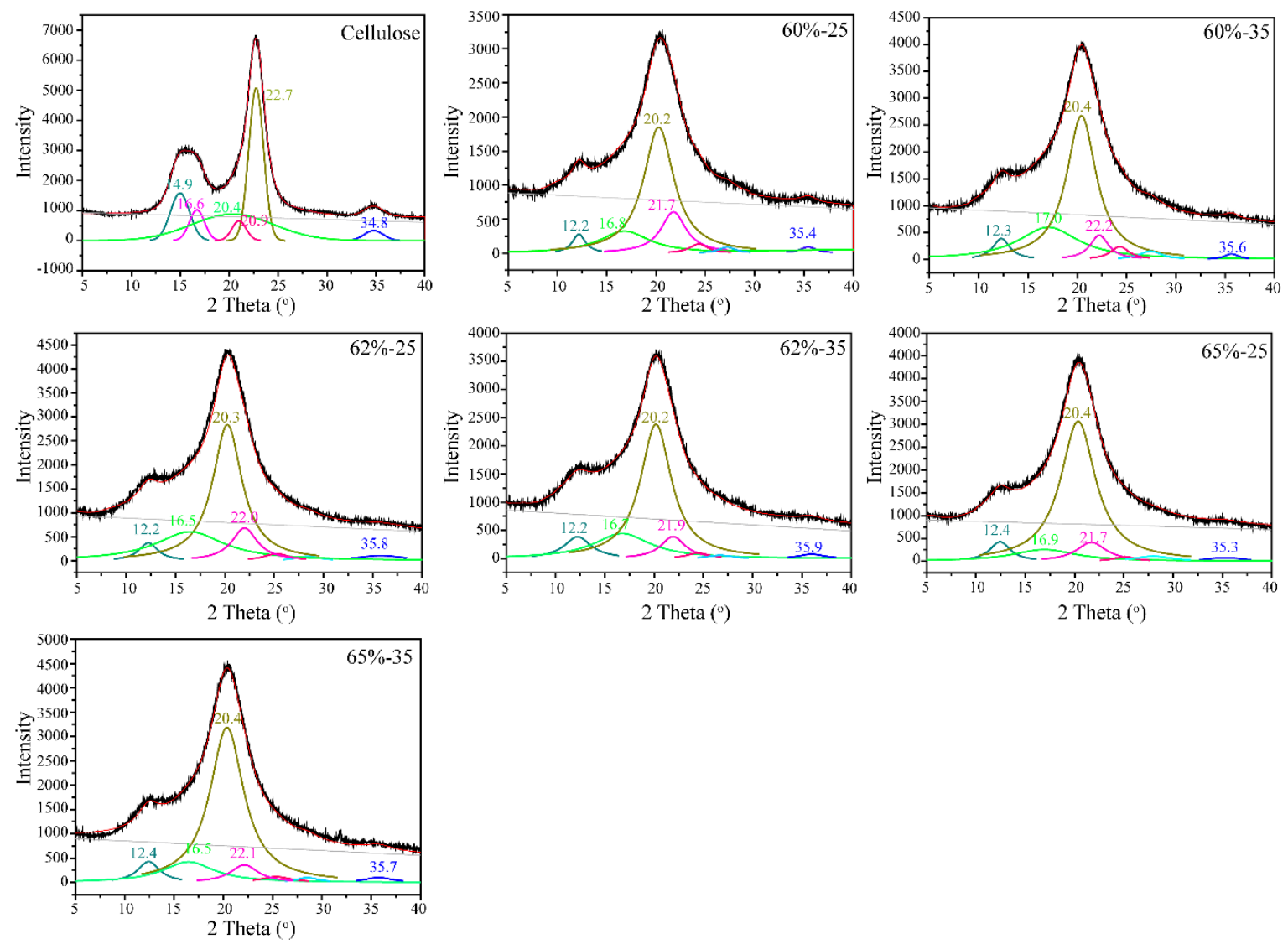

Figure 3. Lorentz deconvolution of the X-ray diffraction (XRD) patterns of cellulose samples. 
For native cellulose, Miller indices of (110), (110), (200), and (004) illustrated the orientation of the original cellulose crystallites along the fiber axis [37]. After the dissolution and regeneration in $\mathrm{LiBr}$ molten salt hydrate, the appearance of the peaks in the $2 \theta$ range of $25^{\circ}$ to $35^{\circ}$ upon the Lorentz deconvolution suggested the random orientation of the cellulose crystallites. These observations indicated that the dissolution and regeneration in $\mathrm{LiBr}$ molten salt hydrates could disrupt the cellulose crystalline structures [37]. As shown in Table 1, the $d$-spacings of 0.595 (110), 0.534 (110), 0.392 (200), and $0.258 \mathrm{~nm}(004)$ are attributed to the cellulose $\mathrm{I}_{\beta}$ crystalline stacks for native cellulose, respectively. Differently, the regenerated cellulose film from $\mathrm{LiBr}$ molten salt hydrate showed no discernible impact on the (110), (200), and (004) planes, but an apparent increase on the (110) plane, further indicating the transformation of cellulose I to cellulose II during the dissolution and regeneration. Additionally, the $L, X$, as well as the $\mathrm{CrI}$ of regenerated cellulose all considerably decreased, indicating that regeneration in $\mathrm{LiBr}$ molten salt hydrate decreased the crystallinity of cellulose and increased the exposure of the cellulose chains, which is in agreement with the ${ }^{13} \mathrm{C}$ NMR data above.

Table 1. The $d$-spacings and the crystalline size of cellulose samples.

\begin{tabular}{ccccccccc}
\hline \multirow{2}{*}{ Sample } & \multicolumn{3}{c}{$d$-Spacing (nm) } & \multicolumn{5}{c}{ Crystalline Size (nm) } \\
\cline { 2 - 9 } & $\overline{1} \mathbf{1 0}$ & $\mathbf{1 1 0}$ & $\mathbf{2 0 0}$ & $\mathbf{0 0 4}$ & $\overline{110}$ & $\mathbf{1 1 0}$ & $\mathbf{2 0 0}$ & $\mathbf{0 0 4}$ \\
\hline Cellulose & 0.595 & 0.534 & 0.392 & 0.258 & 7.35 & 7.84 & 8.79 & 7.47 \\
$60 \%-5$ & 0.738 & 0.433 & 0.385 & 0.258 & 6.57 & 4.59 & 5.58 & 6.52 \\
$60 \%-15$ & 0.725 & 0.439 & 0.411 & 0.252 & 4.80 & 4.49 & 4.94 & 4.57 \\
$60 \%-25$ & 0.731 & 0.437 & 0.409 & 0.254 & 4.64 & 4.45 & 4.52 & 4.47 \\
$60 \%-35$ & 0.720 & 0.435 & 0.400 & 0.252 & 3.54 & 4.28 & 3.94 & 3.79 \\
$62 \%-5$ & 0.720 & 0.440 & 0.410 & 0.253 & 6.44 & 4.54 & 5.42 & 6.47 \\
$62 \%-15$ & 0.725 & 0.442 & 0.406 & 0.254 & 4.69 & 4.42 & 4.85 & 4.47 \\
$62 \%-25$ & 0.725 & 0.437 & 0.404 & 0.251 & 4.31 & 4.37 & 4.38 & 4.30 \\
$62 \%-35$ & 0.714 & 0.440 & 0.406 & 0.250 & 3.45 & 4.20 & 3.82 & 3.75 \\
$65 \%-5$ & 0.720 & 0.439 & 0.408 & 0.255 & 6.38 & 4.47 & 5.36 & 6.31 \\
$65 \%-15$ & 0.708 & 0.435 & 0.406 & 0.254 & 4.60 & 4.33 & 4.67 & 4.35 \\
$65 \%-25$ & 0.714 & 0.435 & 0.409 & 0.254 & 4.28 & 4.29 & 4.29 & 4.17 \\
$65 \%-35$ & 0.714 & 0.435 & 0.402 & 0.251 & 3.28 & 4.12 & 3.57 & 3.37 \\
\hline
\end{tabular}

Table 2. The proportion of crystalline interior chains and the crystalline index of cellulose samples.

\begin{tabular}{cccccc}
\hline \multirow{2}{*}{ Sample } & \multicolumn{3}{c}{ Proportion of Crystalline Interior Chains $(\mathbf{n m})$} & CrI \\
\cline { 2 - 6 } & $\overline{\mathbf{1 1 0}}$ & $\mathbf{1 1 0}$ & $\mathbf{2 0 0}$ & $\mathbf{0 0 4}$ & $\mathbf{( \% )}$ \\
\hline Cellulose & 0.713 & 0.76 & 0.768 & 0.718 & 82.7 \\
$60 \%-5$ & 0.683 & 0.565 & 0.628 & 0.657 & 75.8 \\
$60 \%-15$ & 0.587 & 0.558 & 0.573 & 0.569 & 70.3 \\
$60 \%-25$ & 0.576 & 0.554 & 0.527 & 0.548 & 63.6 \\
$60 \%-35$ & 0.562 & 0.543 & 0.490 & 0.499 & 60.7 \\
$62 \%-5$ & 0.671 & 0.558 & 0.613 & 0.527 & 67.9 \\
$62 \%-15$ & 0.582 & 0.548 & 0.591 & 0.427 & 64.8 \\
$62 \%-25$ & 0.567 & 0.540 & 0.546 & 0.408 & 62.1 \\
$62 \%-35$ & 0.531 & 0.528 & 0.482 & 0.391 & 58.4 \\
$65 \%-5$ & 0.628 & 0.529 & 0.599 & 0.497 & 61.3 \\
$65 \%-15$ & 0.566 & 0.541 & 0.559 & 0.420 & 59.8 \\
$65 \%-25$ & 0.540 & 0.538 & 0.527 & 0.399 & 55.8 \\
$65 \%-35$ & 0.519 & 0.508 & 0.436 & 0.383 & 50.5 \\
\hline
\end{tabular}

\subsection{SEM Analysis}

In order to investigate the effects of the $\mathrm{LiBr}$ concentrations and dissolving time on the surface morphology of the regenerated films, SEM analysis was conducted, as shown in Figure 4. From Figure 4A, cellulose fibers were still clearly visible in the film that was prepared in $60 \mathrm{wt} \% \mathrm{LiBr}$ 
molten salt hydrate for $5 \mathrm{~min}$. This result indicated that low $\mathrm{LiBr}$ concentration and short dissolving time were insufficient to completely dissolve cellulose [36]. With the extension of dissolving time from $5 \mathrm{~min}$ to $15 \mathrm{~min}(\mathrm{~B})$, and then to $25 \mathrm{~min}(\mathrm{C})$, the cellulose fibers remarkably reduced in the films, and finally became almost invisible at $35 \mathrm{~min}$ (D). These results indicated that extending dissolving time in LiBr molten salt hydrate with low concentration could increase the dissolving of cellulose fibers, but not totally dissolve. Increasing the $\mathrm{LiBr}$ concentration to $62 \mathrm{wt} \%$ resulted in the significant decrease of the cellulose fibers after $5 \mathrm{~min}(\mathrm{E})$, and then disappeared after $15 \mathrm{~min}(\mathrm{~F})$. For the films that were regenerated in $65 \mathrm{wt} \% \mathrm{LiBr}$, the cellulose fibers were almost invisible after $5 \mathrm{~min}$ (I). These are probably due to the destruction of the cellulose crystalline structure and the increased dissolution of cellulose with the development of the $\mathrm{LiBr}$ concentration and dissolution time. However, small nodules and contours were observed in the films $(\mathrm{F}-\mathrm{L})$, which resulted from the formation of strong hydrogen bonding of cellulose during film-forming [38,39].
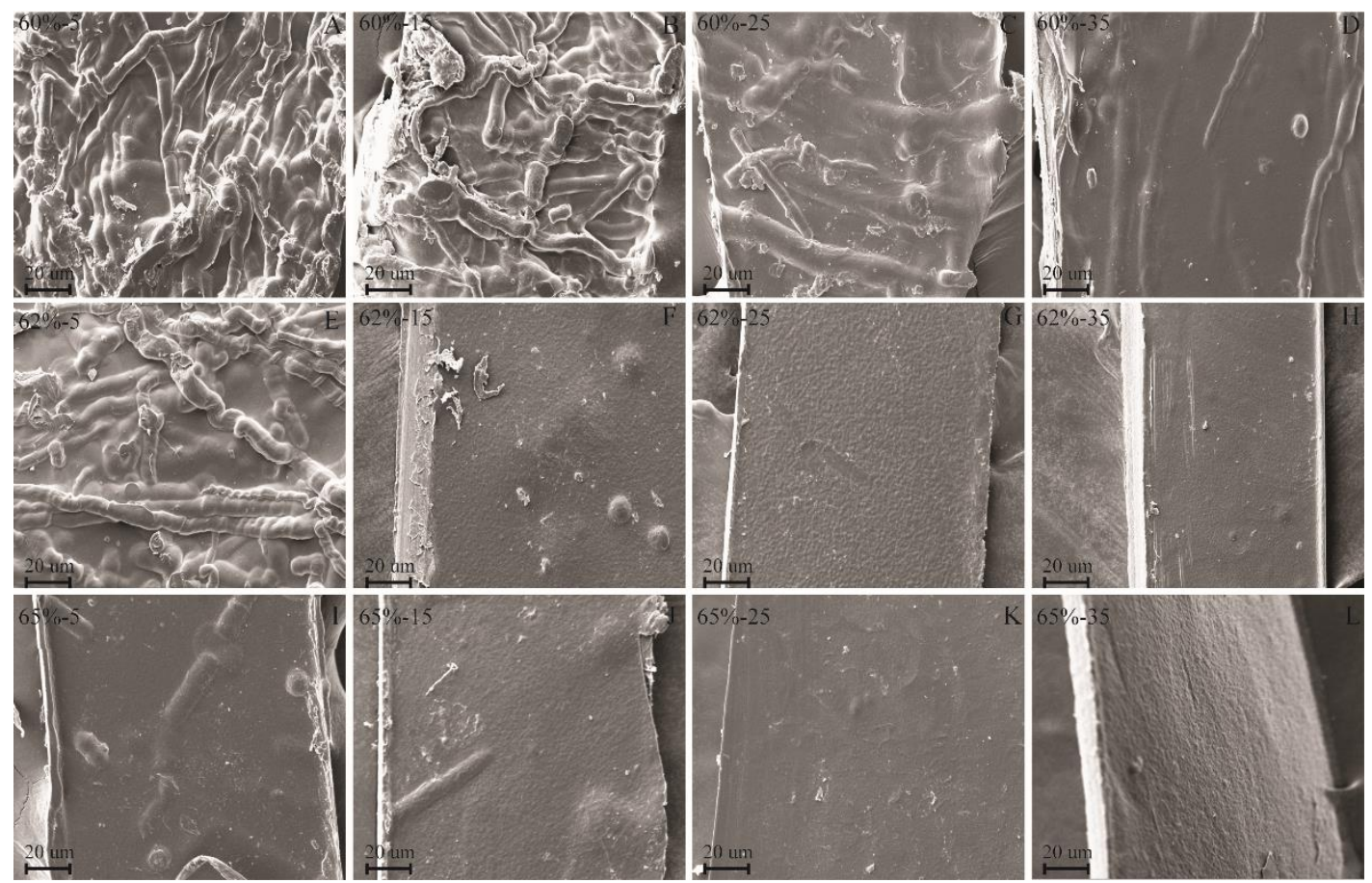

Figure 4. Scanning electron microscopy (SEM) images of the regenerated cellulose films ((A) for 60\%-5, (B) for 60\%-15, (C) for 60\%-25, (D) for 60\%-35, (E) for 62\%-5, (F) for 62\%-15, (G) for 62\%-25, (H) for $62 \%-35$, (I) for 65\%-5, (J) for 65\%-15, (K) for 65\%-25 and (L) for 65\%-35).

\subsection{UV-Vis Spectrophotometric Analysis}

The transparency of the films prepared in $\mathrm{LiBr}$ solutions with various concentrations and dissolving time was evaluated using UV-Vis spectrophotometer, as shown in Figure 5. In the visible region (400-800 nm), the light transmittance of films was improved with the increment of $\mathrm{LiBr}$ concentration and the extension of dissolving time (Figure $5 \mathrm{~d}$ ). For the films prepared in $60 \mathrm{wt} \%$ and $62 \mathrm{wt} \% \mathrm{LiBr}$ solution, the maximum light transmittances of films were only $72 \%$ and $73 \%$, respectively (Figure 5a,b). Comparatively, the light transmittance of the films regenerated in $65 \mathrm{wt} \%$ LiBr solution was above $80 \%$ (Figure $5 \mathrm{c}$ ). Similar results could be observed on the cellulose films regenerated in dimethylacetamide/lithium chloride (DMAc/LiCl), 1-ally-3-methylimidazolium ([Amim]Cl), and $\mathrm{LiOH} /$ urea $/ \mathrm{H}_{2} \mathrm{O}$ with the extension of dissolving time $[17,18,36]$. Figure 5 also lists the photographs of the transparency of the films that were prepared in $65 \mathrm{wt} \% \mathrm{LiBr}$ with different dissolving time. As shown in Figure 5e, the longer the dissolving time was, the higher the optical transparent of the films became. These are probably due to the decrease of the crystallinity of cellulose and the complete 
dissolution of cellulose with the increase of the $\mathrm{LiBr}$ concentration and the extension of dissolving time. However, the surface of the film $65 \%-40$ became damaged, which is probably due to the dramatic disruption of the crystalline structure of cellulose under severe dissolving conditions. Although SEM images showed the disappearance of cellulose fibers in $62 \mathrm{wt} \% \mathrm{LiBr}$ solution after $15 \mathrm{~min}$, the light transmittances of resultant films were still lower than $80 \%$, suggesting that cellulose was not completely dissolved in low-concentrations (<65 wt \%) LiBr solutions.
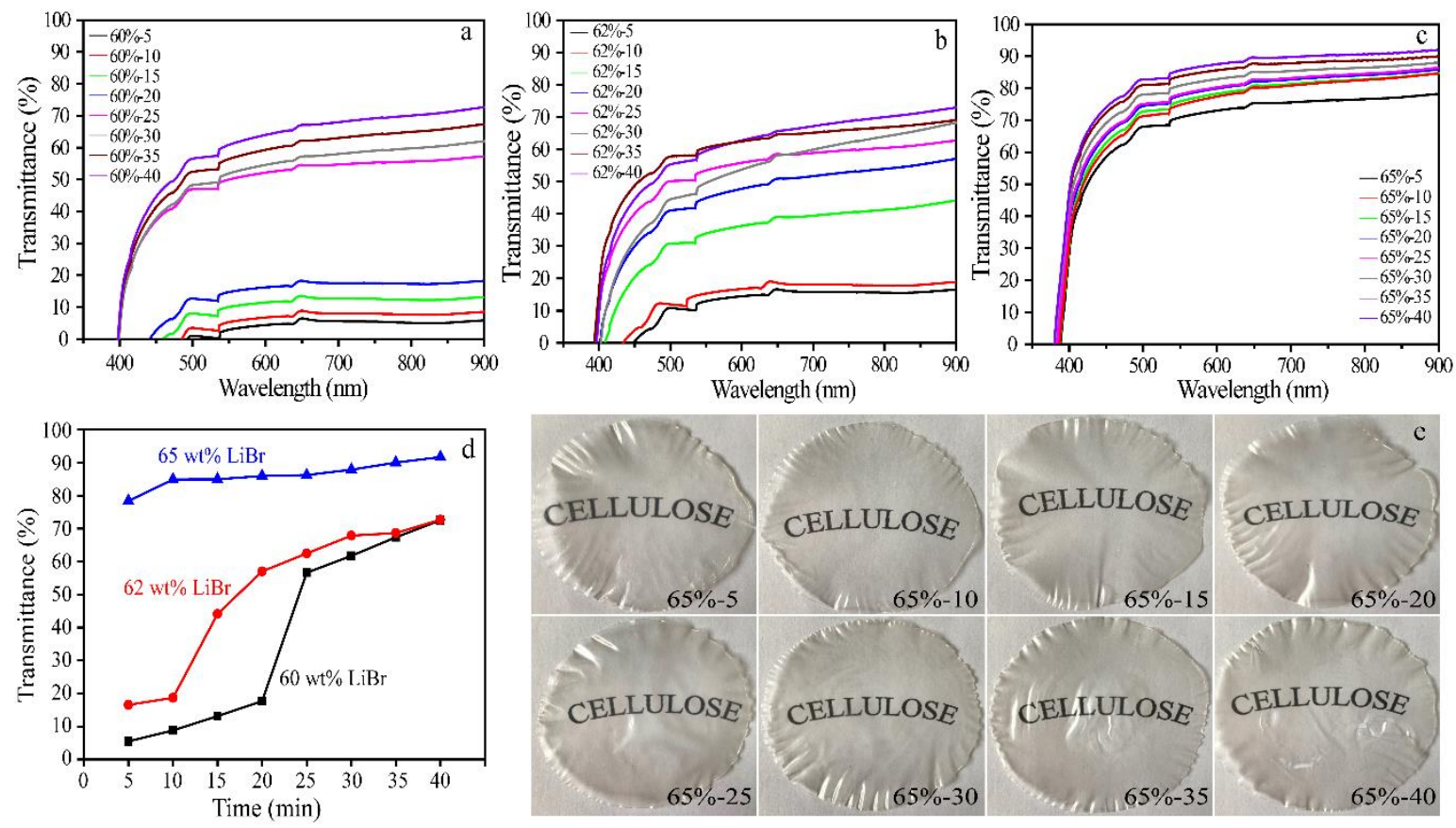

Figure 5. Light transmittance graphs of cellulose films prepared under various conditions (a-c), and plotting the light transmittance of cellulose films (d), and the photographs of cellulose films prepared in $65 \mathrm{wt} \% \mathrm{LiBr}$ molten salt hydrate with varied dissolution time (e).

\subsection{Mechanical Properties of Films}

Figure 6 shows the tensile stress-strain curves of the regenerated cellulose films prepared in 60, 62 and $65 \mathrm{wt} \%$ LiBr molten salt hydrates with different dissolving time, respectively, and the corresponding tensile strength, Young's modulus, and elongation at break of films are summarized in Table 3. Apparently, in $60 \mathrm{wt} \% \mathrm{LiBr}$ molten salt hydrate (Figure 6A), extending the dissolving time from 5 to 20 min resulted in an increment of the tensile strength and elongation at the break of the cellulose films from approximately $4 \mathrm{MPa}$ and $7 \%$ to $34 \mathrm{MPa}$ and $12 \%$, respectively. These results are probably due to the increased dissolution of cellulose. Further extending the dissolving time from 20 to $30 \mathrm{~min}$, and to $40 \mathrm{~min}$ led to an increase of the tensile strength of films from approximately 34 to $38 \mathrm{MPa}$, and then decreased to approximately $14 \mathrm{MPa}$, while the elongation at break of films decreased from approximately $12 \%$ to $5 \%$. This is probably attributed to the severe disruption of the crystalline structure of cellulose. For the cellulose films that were regenerated in $62 \mathrm{wt} \% \mathrm{LiBr}$ molten salt hydrate (Figure 6B), the tensile strength and elongation at break of the cellulose films increased from approximately $21 \mathrm{MPa}$ and $7 \%$ to $41 \mathrm{MPa}$ and 16\%, respectively, when the dissolving time extended from 5 to $15 \mathrm{~min}$. The tensile strength of films reached to the maximum of approximately $53 \mathrm{MPa}$ at $30 \mathrm{~min}$ dissolving time, and then decreased with further extension of dissolving time. For example, the tensile strength dropped to approximately $23 \mathrm{MPa}$ at $40 \mathrm{~min}$. Differently, the elongation at break reached the maximum $(16 \%)$ at $15 \mathrm{~min}$ and then declined to $6 \%$ with the extension of dissolving time to $40 \mathrm{~min}$. Similar trends were observed for the films prepared in $65 \mathrm{wt} \% \mathrm{LiBr}$ molten salt hydrate (Figure 6C), but higher tensile strength $(67 \mathrm{MPa})$ and elongation at break $(26 \%)$ 
were reached, suggesting that the sufficient and complete dissolution of cellulose in $65 \mathrm{wt} \% \mathrm{LiBr}$ solution generated not only more homogeneous and transparent (Figures 4 and 5), but also stronger, films. However, when extending the dissolving time to $40 \mathrm{~min}$, the cellulose film (65\%-40) was too fragile to test the mechanical properties (as shown in Figure 5e). Comparatively, the tensile strength and Young's modulus of the cellulose films regenerated in $\mathrm{LiBr}$ molten salt hydrate from kraft pulp were lower than those of other regenerated cellulose films [40]. This could probably be attributed to the cellulose obtained from different sources that is used in these studies, as well as the various regeneration conditions.
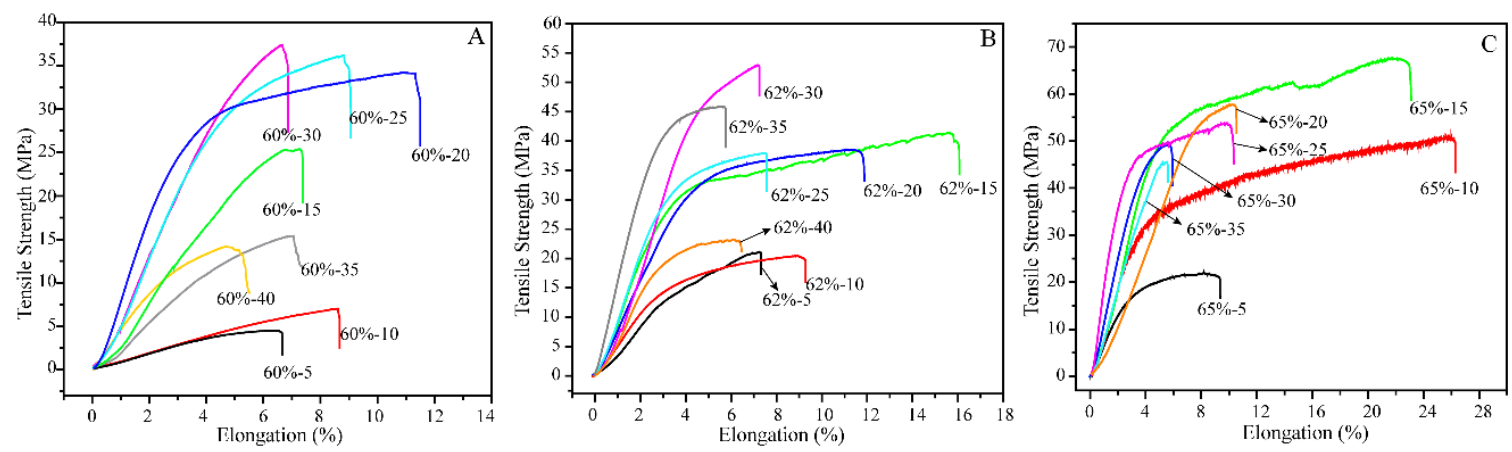

Figure 6. Tensile strain curves of cellulose films regenerated in $60 \mathrm{wt} \%$ (A), $62 \mathrm{wt} \%$ (B) and $65 \mathrm{wt} \%$ (C) LiBr molten salt hydrate with different dissolving time.

Table 3. Mechanical properties of cellulose films prepared under different conditions.

\begin{tabular}{cccc}
\hline Sample & Tensile Strength (MPa) & Young's Modulus (MPa) & Elongation at Break (\%) \\
\hline $60 \%-5$ & 4.19 & 343.02 & 6.68 \\
$60 \%-10$ & 6.74 & 398.71 & 8.75 \\
$60 \%-15$ & 25.71 & 394.33 & 7.26 \\
$60 \%-20$ & 33.79 & 727.40 & 11.60 \\
$60 \%-25$ & 36.80 & 568.36 & 8.86 \\
$60 \%-30$ & 37.51 & 396.06 & 6.87 \\
$60 \%-35$ & 15.07 & 355.28 & 7.16 \\
$60 \%-40$ & 13.93 & 493.76 & 5.17 \\
$62 \%-5$ & 20.93 & 720.58 & 7.31 \\
$62 \%-10$ & 20.30 & 573.22 & 9.23 \\
$62 \%-15$ & 41.22 & 1210.99 & 16.09 \\
$62 \%-20$ & 38.32 & 897.46 & 11.57 \\
$62 \%-25$ & 37.91 & 741.68 & 7.49 \\
$62 \%-30$ & 52.60 & 964.86 & 7.27 \\
$62 \%-35$ & 45.77 & 1277.90 & 5.71 \\
$62 \%-40$ & 22.79 & 886.71 & 6.35 \\
$65 \%-5$ & 20.69 & 771.60 & 9.23 \\
$65 \%-10$ & 50.67 & 771.65 & 26.03 \\
$65 \%-15$ & 66.80 & 1506.63 & 22.96 \\
$65 \%-20$ & 57.59 & 1362.12 & 10.43 \\
$65 \%-25$ & 53.75 & 835.02 & 9.97 \\
$65 \%-30$ & 49.38 & 1433.00 & 5.69 \\
$65 \%-35$ & 42.92 & 1403.95 & 5.58 \\
\hline
\end{tabular}

It is worth mentioning that the films prepared in $\mathrm{LiBr}$ molten salt hydrate with appropriate dissolving time had high toughness because of the high ultimate tensile strength and failure strain [41]. Usually, the elongation at break of the cellulose films regenerated in ionic liquid [40], $\mathrm{NaOH} /$ urea [42] or $\mathrm{DMAc} / \mathrm{LiCl}$ [17] was lower than $15 \%$. The films prepared in the present study had the maximum elongation at break as high as $26 \%$. The tensile strength of the cellulose films that were prepared from 
kraft pulp in LiBr molten salt hydrate was higher than that of widely used commercial polyolefin films, such as polypropylene (PP) and polyethylene (PE) films [43]. With good strength and toughness, in addition to biodegradability, the cellulose films that were prepared in this study have great potential to replace non-biodegradable PP and PE in the packaging area.

\section{Conclusions}

In the present study, the regenerated cellulose films were prepared from kraft pulp in $\mathrm{LiBr}$ molten salt hydrate under different conditions ( $\mathrm{LiBr}$ concentrations and dissolving time). FT-IR and $\mathrm{CP} / \mathrm{MAS}{ }^{13} \mathrm{C}$ NMR studies indicated that inter- and intra-cellulose hydrogen bonds were broken during the dissolution and regeneration, and as a result, the crystalline structure of cellulose was disrupted. The results of XRD showed that the regeneration in $\mathrm{LiBr}$ molten salt hydrate converted the polymorphism of cellulose from I to II, and meanwhile it reduced its crystallinity, which was consistent with the FT-IR and ${ }^{13} \mathrm{C}$ NMR results. The good dissolution of cellulose in $\mathrm{LiBr}$ molten salt hydrate was confirmed by SEM imaging, and no cellulose fibers were visible when kraft pulp was dissolved in $\mathrm{LiBr}$ solution with $62 \mathrm{wt} \%$ or above concentration for sufficient dissolving time. The resultant cellulose films had high transparency to visible light. The films that were regenerated in $65 \mathrm{wt} \% \mathrm{LiBr}$ molten salt hydrate after 10 and 15 min exhibited good toughness with high elongation at break up to $26 \%$ and good tensile strength of $67 \mathrm{MPa}$, respectively. The films are anticipated to have great potential as packaging films.

Author Contributions: X.P. initiated this project; X.Z. designed the experiments, prepared the cellulose films and wrote the manuscript; N.X. helped to analyze the mechanical properties of films; H.W. and C.L. analyzed the FT-IR and NMR spectra; X.Z., N.X., H.W., C.L. and X.P. discussed the results and revised the manuscript.

Acknowledgments: The authors thank the China Scholarship Council (CSC) for supporting Xueqin Zhang to conduct this research at the University of Wisconsin-Madison. This work was partially supported by the National Science Foundation grant CBET1159561 to Xuejun Pan and the National Program for Support of Top-notch Young Professionals to Chuanfu Liu.

Conflicts of Interest: The authors declare no conflict of interest.

\section{References}

1. Tardy, A.; Nicolas, J.; Gigmes, D.; Lefay, C.; Guillaneuf, Y. Radical ring-opening polymerization: Scope, limitations, and application to (bio)degradable materials. Chem. Rev. 2017, 117, 1319-1406. [CrossRef] [PubMed]

2. Sanla-Ead, N.; Jangchud, A.; Chonhenchob, V.; Suppakul, P. Antimicrobial activity of cinnamaldehyde and eugenol and their activity after incorporation into cellulose-based packaging films. Packag. Technol. Sci. 2012, 25, 7-17. [CrossRef]

3. Ma, J.; Zhu, W.; Min, D.; Wang, Z.; Zhou, X. Preparation of antibacterial self-reinforced zinc oxide-cellulose composite by the synthesis of $\mathrm{ZnO}$ in partially dissolved cellulose. Cellulose 2016, 23, 3199-3208. [CrossRef]

4. Cheng, D.; An, X.Y.; Zhang, J.H.; Tian, X.F.; He, Z.B.; Wen, Y.B.; Ni, Y.H. Facile preparation of regenerated cellulose film from cotton linter using organic electrolyte solution (OES). Cellulose 2017, 24, 1631-1639. [CrossRef]

5. Hinner, L.P.; Wissner, J.L.; Beurer, A.; Nebel, B.A.; Hauer, B. Homogeneous vinyl ester-based synthesis of different cellulose derivatives in 1-ethyl-3-methyl-imidazolium acetate. Green Chem. 2016, 18, 6099-6107. [CrossRef]

6. Guillou, J.; Lavadiya, D.N.; Munro, T.; Fronk, T.; Ban, H. From lignocellulose to biocomposite: Multi-level modelling and experimental investigation of the thermal properties of kenaf fiber reinforced composites based on constituent materials. Appl. Therm. Eng. 2018, 128, 1372-1381. [CrossRef]

7. Dupont, A.L. Cellulose in lithium chloride/N,N-dimethylacetamide, optimisation of a dissolution method using paper substrates and stability of the solutions. Polymer 2003, 44, 4117-4126. [CrossRef]

8. Stryuk, S.; Eckelt, J.; Wolf, B. Solutions of cellulose in DMAc + LiCl: Migration of the solute in an electrical field. Cellulose 2005, 12, 145-149. [CrossRef] 
9. Cazón, P.; Velazquez, G.; Ramírez, J.A.; Vázquez, M. Polysaccharide-based films and coatings for food packaging: A review. Food Hydrocolloid. 2017, 68, 136-148. [CrossRef]

10. Swatloski, R.P.; Spear, S.K.; Holbrey, J.D.; Rogers, R.D. Dissolution of cellose with ionic liquids. J. Am. Chem. Soc. 2002, 124, 4974-4975. [CrossRef] [PubMed]

11. Zhang, X.Q.; Wang, H.H.; Liu, C.F.; Zhang, A.P.; Ren, J.L. Synthesis of thermoplastic xylan-lactide copolymer with amidine-mediated organocatalyst in ionic liquid. Sci. Rep. 2017, 7, 1-7. [CrossRef] [PubMed]

12. Rynkowska, E.; Fatyeyeva, k.; Kujawa, J.; Dzieszkowski, K.; Wolan, A.; Kujawski, W. The effect of reactive ionic liquid or plasticizer incorporation on the physicochemical and transport properties of cellulose acetate propionate-based membranes. Polymers 2018, 10, 86. [CrossRef]

13. Zhang, H.; Xu, Y.G.; Li, Y.Q.; Lu, Z.X.; Cao, S.L.; Fan, M.Z.; Huang, L.L.; Chen, L.H. Facile cellulose dissolution and characterization in the newly synthesized 1,3-diallyl-2-ethylimidazolium acetate ionic liquid. Polymers 2017, 9, 526. [CrossRef]

14. Mendes, F.R.S.; Bastos, M.S.R.; Mendes, L.G.; Silva, A.R.A.; Sousa, F.D.; Monteiro-Moreira, A.C.O.; Cheng, H.N.; Biswas, A.; Moreira, R.A. Preparation and evaluation of hemicellulose films and their blends. Food Hydrocolloid. 2017, 70, 181-190. [CrossRef]

15. Chinsirikul, W.; Rojsatean, J.; Hararak, B.; Kerddonfag, N.; Aontee, A.; Jaieau, K.; Kumsang, P.; Sripethdee, C. Flexible and tough poly(lactic acid) films for packaging applications: Property and processability improvement by effective reactive blending. Packag. Technol. Sci. 2015, 28, 741-759. [CrossRef]

16. Jambeck, J.R.; Geter, R.; Wilcox, C.; Siegler, T.R.; Perryman, M.; Andrady, A.; Narayan, R.; Law, K.L. Plastic waste inputs from land into the ocean. Science 2015, 347, 768-771. [CrossRef] [PubMed]

17. Yudianti, R.; Syampurwadi, A.; Onggo, H.; Karina, M.; Uyama, H.; Azuma, J. Properties of bacterial cellulose transparent film regenerated from dimethylacetamide-LiCl solution. Polym. Advan. Technol. 2016, 27, 1102-1107. [CrossRef]

18. Quanling, Y.; Tsuguyuki, S.; Akira, I. Transparent, flexible, and high-strength regenerated cellulose/saponite nanocomposite films with high gas barrier properties. J. Appl. Polym. Sci. 2013, 130, 3168-3174.

19. Ashok, B.; Reddy, K.O.; Madhukar, K.; Cai, J.; Zhang, L.; Rajulu, A.V. Properties of cellulose/thespesia lampas short fibers bio-composite films. Carbohydr. Polym. 2015, 127, 110-115. [CrossRef] [PubMed]

20. Huber, T.; Müssig, J.; Curnow, O.; Pang, S.; Bickerton, S.; Staiger, M.P. A critical review of all-cellulose composites. J. Mater. Sci. 2012, 47, 1171-1186. [CrossRef]

21. Zhang, J.M.; Luo, N.; Zhang, X.Y.; Xu, L.L.; Wu, L.; Yu, J.; He, J.S.; Zhang, J. All-cellulose nanocomposites reinforced with in situ retained cellulose nanocrystals during selective dissolution of cellulose in an ionic liquid. ACS Sustain. Chem. Eng. 2016, 4, 4417-4423. [CrossRef]

22. Yan, C.; Huiquan, L.; Yi, Z.; Jun, Z.; Jiasong, H. Structure and properties of novel regenerated cellulose films prepared from cornhusk cellulose in room temperature ionic liquids. J. Appl. Polym. Sci. 2010, 116, 547-554.

23. Reddy, K.O.; Zhang, J.; Zhang, J.; Rajulu, A.V. Preparation and properties of self-reinforced cellulose composite films from agave microfibrils using an ionic liquid. Carbohydr. Polym. 2014, 114, 537-545. [CrossRef] [PubMed]

24. Pang, J.H.; Liu, X.; Wu, M.; Wu, Y.Y.; Zhang, X.M.; Sun, R.C. Fabrication and characterization of regenerated cellulose films using different ionic liquids. J. Spectrosc. 2014, 2014, 8. [CrossRef]

25. Duchemin, B.J.C.; Mathew, A.P.; Oksman, K. All-cellulose composites by partial dissolution in the ionic liquid 1-butyl-3-methylimidazolium chloride. Compos. Part. A: Appl. Sci. Manuf. 2009, 40, 2031-2037. [CrossRef]

26. Yang, Y.J.; Shin, J.M.; Kang, T.H.; Kimura, S.; Wada, M.; Kim, U.J. Cellulose dissolution in aqueous lithium bromide solutions. Cellulose 2014, 21, 1175-1181. [CrossRef]

27. Deng, W.H.; Kennedy, J.R.; Tsilomelekis, G.; Zheng, W.Q.; Nikolakis, V. Cellulose hydrolysis in acidified libr molten salt hydrate media. Ind. Eng. Chem. Res. 2015, 54, 5226-5236. [CrossRef]

28. Montero, C.; Clair, B.; Alméras, T.; Lee, A.v.d.; Gril, J. Relationship between wood elastic strain under bending and cellulose crystal strain. Compos. Sci. Technol. 2012, 72, 175-181. [CrossRef]

29. Popescu, M.C.; Popescu, C.M.; Lisa, G.; Sakata, Y. Evaluation of morphological and chemical aspects of different wood species by spectroscopy and thermal methods. J. Mol. Struct. 2011, 988, 65-72. [CrossRef]

30. Davidson, T.C.; Newman, R.H.; Ryan, M.J. Variations in the fibre repeat between samples of cellulose I from different sources. Carbohydr. Res. 2004, 339, 2889-2893. [CrossRef] [PubMed] 
31. Segal, L.; Creely, J.J.; Jr, A.E.M.; Conrad, C.M. An empirical method for estimating the degree of crystallinity of native cellulose using the x-ray diffractometer. Text. Res. J. 2016, 29, 786-794. [CrossRef]

32. Chen, C.Y.; Chen, M.J.; Zhang, X.Q.; Liu, C.F.; Sun, R.C. Per-O-acetylation of cellulose in dimethyl sulfoxide with catalyzed transesterification. J. Agric. Food Chem. 2014, 62, 3446-3452. [CrossRef] [PubMed]

33. Lee, C.M.; Kubicki, J.D.; Fan, B.; Zhong, L.; Jarvis, M.C.; Kim, S.H. Hydrogen-bonding network and OH stretch vibration of cellulose: Comparison of computational modeling with polarized IR and SFG spectra. J. Phys. Chem. B 2015, 119, 15138-15149. [CrossRef] [PubMed]

34. Maunu, S.; Liitiä, T.; Kauliomäki, S.; Hortling, B.; Sundquist, J. ${ }^{13} \mathrm{C}$ CP/MAS NMR investigations of cellulose polymorphs in different pulps. Cellulose 2000, 7, 147-159. [CrossRef]

35. Idström, A.; Schantz, S.; Sundberg, J.; Chmelka, B.F.; Gatenholm, P.; Nordstierna, L. ${ }^{13}$ C NMR assignments of regenerated cellulose from solid-state 2D NMR spectroscopy. Carbohydr. Polym. 2016, 151, 480-487. [CrossRef] [PubMed]

36. Zhang, J.M.; Luo, N.; Zhang, X.Y.; Xu, L.L.; Wu, J.; Yu, J.; He, J.S.; Zhang, J. All-cellulose nanocomposites reinforced with in situ retained cellulose nanocrystals during selective dissolution of cellulose in an ionic liquid. ACS Sustain. Chem. Eng. 2016, 4, 4417-4423. [CrossRef]

37. French, A.D. Idealized powder diffraction patterns for cellulose polymorphs. Cellulose 2014, 21, 885-896. [CrossRef]

38. Zhong, L.X.; Peng, X.W.; Yang, D.; Cao, X.F.; Sun, R.C. Long-chain anhydride modification: A new strategy for preparing xylan films. J. Agric. Food Chem. 2013, 61, 655-661. [CrossRef] [PubMed]

39. Pang, J.H.; Wu, M.; Zhang, Q.H.; Tan, X.; Xu, F.; Zhang, X.M.; Sun, R.C. Comparison of physical properties of regenerated cellulose films fabricated with different cellulose feedstocks in ionic liquid. Carbohydr. Polym. 2015, 121, 71-78. [CrossRef] [PubMed]

40. Reddy, K.O.; Maheswari, C.U.; Dhlamini, M.S.; Mothudi, B.M.; Zhang, J.; Zhang, J.; Nagarajan, R.; Rajulu, A.V. Preparation and characterization of regenerated cellulose films using borassus fruit fibers and an ionic liquid. Carbohydr. Polym. 2017, 160, 203-211. [CrossRef] [PubMed]

41. Zhang, T.P.; Zhang, X.F.; Chen, Y.W.; Duan, Y.X.; Zhang, J.M. Green fabrication of regenerated cellulose/graphene films with simultaneous improvement of strength and toughness by tailoring the nanofiber diameter. ACS Sustain. Chem. Eng. 2018, 6, 1271-1278. [CrossRef]

42. Tanvir, A.; Al-Maadeed, M.A.; Hassan, M.K. Secondary chain motion and mechanical properties of irradiated regenerated cellulose films. Starch-Starke 2017, 69, 1-8. [CrossRef]

43. Ding, H. Handbook of plastic industry; Chemical Industry Press: Beijing, China, 1995. 